$12^{\text {th }}$ International Conference on Retailing and Commercial Distribution Teaching and Research Issues,

EAERCD, Surrey University, 15-17 July 2009.

\title{
Using authentic 3D product visualisation for an electrical online retailer
}

\author{
Raed Algharabat \\ Brunel Business School, Marketing Department, Brunel University, U.K. \\ Phone: +44 (0) 1895 266251, Fax: +44 (0) 1895269775 \\ Raed.Algharabat@brunel.ac.uk \\ Charles Dennis \\ Brunel Business School, Marketing Department, Brunel University, U.K. \\ Phone: +44 (0) 1895 265242, Fax: +44 (0) 1895269775 \\ Charles.Dennis@brunel.ac.uk
}

Raed Algharabat is a Ph.D. student at Brunel University, London, U.K. Raed's research area is e-retailing, particularly, virtual models and their impact on consumers' behaviour within the online retailer context.

Charles Dennis is a Senior Lecturer at Brunel University, London, UK. His teaching and research area is (e-) retail and consumer behaviour - the vital final link of the Marketing process - satisfying the end consumer. Charles is a Chartered Marketer and has been elected as a Fellow of the Chartered Institute of Marketing for work helping to modernise the teaching of the discipline. Charles was awarded the Vice Chancellor's Award for Teaching Excellence for improving the interactive student learning experience. Charles's publications include Marketing the e-Business, $\left(1^{\text {st }} \& 2^{\text {nd }}\right.$ editions) (joint-authored with Dr Lisa Harris), the research-based $e$-Retailing (joint-authored with Professor Bill Merrilees and Dr Tino Fenech) and research monograph Objects of Desire: Consumer Behaviour in Shopping Centre Choice. His research into shopping styles has received extensive coverage in the popular media. 


\title{
Using Authentic 3D Product Visualisation for an Electrical Online Retailer
}

\begin{abstract}
This study investigates the effects of authentic three dimensional (3D) product visualisation versus 3D telepresence on consumers' virtual experience. A hypothetical electrical retailer Web site presents a variety of laptops using 3D product visualisations for the within-subjects laboratory experiments. The first experiment uses two-way repeated measures ANOVA to determine the effects of the antecedents on 3D authenticity. In a second experiment, a oneway ANOVA compares telepresence and authenticity scores. This research uses a U.K. sample to investigate the effects of control and animated colours on 3D authenticity and the effects of 3D authenticity on experiential and instrumental values. The results reveal significant differences between telepresence and authenticity constructs. Authenticity is more significant in simulating an online retailer's products, and control and animated colours represent the main antecedents of authenticity. Moreover, experiential and instrumental values represent the main consequences of $3 \mathrm{D}$ authenticity.
\end{abstract}

-Key words: control; animated colours; telepresence; authenticity; virtual experience.

\section{-Paper type: Research paper.}

\subsection{Introduction}

According to Steuer (1992, p.78) virtual reality (VR) is "a real or simulated environment in which a perceiver experiences telepresence". In contrast, virtual experience derives from VR and can be defined as "psychological and emotional states that consumers undergo while interacting with a 3D environment" (Li et al. 2001, p. 14). A three-dimensional (3D) presentation enables consumers to interact with products, enriches their learning processes, and creates a sense of being in a simulated real world. Furthermore, direct and virtual experiences combine within VR, such that the latter enhances and enriches the overall experience because consumers use almost all of their senses when interacting with a 3D product visualisation (Klein, 2003; Li et al., 2001, 2002, 2003). Despite widespread discussions and various definitions of telepresence, no existing scales tap the concept of using virtual environment (in a non-immersive VR) to reflect consumers' experience. For an experience to become a virtual one marketers should use "authentic objects" in which the 
users interact with objects which they can find in real life aspects such as clothes or electricals.

Previous scales of telepresence or presence have been built upon the base of using phrases such as illusion or transportation to another place. However, we believe that the previous scales would not help marketers to measure 3D online products as real representative of the offline products. We therefore discuss the notion of telepresence and its antecedents in the human computer interaction (HCI) field, then explain telepresence applications in an online retail context. We also offer a new definition and measurement scale for the construct of authenticity, its antecedents and consequences focusing on a fictitious electrical retailer, which offers, the focal product, laptops. Furthermore, this paper discusses the consequences of 3D authenticity; experiential and instrumental values. Finally, we develop and test a structural model (Figure 1) proposing relationships between control, animated colours, authenticity, and consumer value variables.

\subsection{Theoretical Background}

\subsection{D Telepresence in Immersive Virtual Realities}

Steuer (1992) focused on human experience, not technological hardware, to determine and define virtual reality. Human experience is key to defining virtual reality and the concept of presence. While presence refers to: "the experience of one's physical environment; it refers not to one's surroundings as they exist in the physical world, but to the perception of those surroundings as mediated by both automatic and controlled mental process" (p.76), telepresence refers to "the experience of presence in an environment by means of a communication medium" (p.76). Steuer (1992) stated that vividness, interactivity, and user characteristics are the main determinants of telepresnece.

Sheridan (1992) distinguished between virtual presence and telepresence, pointing out that presence relates to the sense of being in computer-mediated environment, whereas, telepresence relates to the sense of being in any real remote location.

Based on the previous scholarly literature, Lombard and Ditton (1997) identified six different taxonomies of presence (i.e., social richness, realism, transportation, immersion, social actor 
within medium and medium as social actor). However, only two types of presence appear in the online retail context.

The first is presence as transportation. In his explanation of presence, Biocca (1997) states that the first version of presence was referred to as "telepresence", or the illusion of being in a place far from the physical body. This conceptualisation of presence relates to transporting a user, self, or place, to another place. According to Heeter (1992) virtual worlds require the subjective experience of presence or "being there", and creating a sense of presence is a matter of simulating the range and intensity of the natural stimuli that human senses can select and interpret when perceiving the natural world. This author classifies the subjective experience of presence into three parts: personal, social and environment.

The second form is presence in a social sense, such that other beings exist in the VR world with whom users can interact (e.g., avatars). Authors such as Heeter (1997) and Lombard and Ditton (1997) empirically test this concept.

Previous research on telepresence (e.g., Biocca, 1997; Heeter, 1992; Lombard and Ditton, 1997; Sheridan, 1992) thus reveals several key findings. First, researchers from different fields (e.g., communication, business, psychology, and HCI) use different terms (e.g., presence, telepresence, virtual presence, immersion, mediated presence) to describe the same concept. However, some debate remains regarding definitions of presence and telepresence. Second, previous research uses presence and telepresence to explain VR experience, though these conceptualisations have depended on the level of technology (e.g., Biocca, 1992; Steuer, 1992; Sheridan, 1992). Whereas in the past researchers used display interface technologies such as goggles, head-mounted visors, data gloves, joysticks, head trackers and televisions to identify and measure presence (e.g., Biocca, 1992; Heeter, 1992; Lombard and Ditton, 1997; Sheridan 1992; Steuer, 1992; Witmer and Singer, 1998), more recent technological developments can "transport" users to other places, where they can see and interact with other intelligent beings (e.g., avatars in Second Life, chat rooms, online communities), without forcing them to wear technological devices. Therefore, neither using the above terminologies, nor their definitions could help marketers to understand how using 3D product visualisation may help consumers to understand the effect of 3D product visualisation on consumers' experience.

\subsection{Telepresence and the Online Retailer Studies (Non-Immersive Virtual Realities)}


The influence of 3D on consumers' experiences has been empirically tested by many scholars. For example, Li et al. (2002) and Suh and Lee (2005), Hopkins, Raymond and Mitra (2004) and Suh and Chang (2006) found that 3D product simulation has a direct influence on product knowledge, product attitude, brand attitudes and purchase intention.

Klein (2003) used Macromedia's Authorware (C) 3.0 and 4.0, which the author called simple technology, to examine the effects of telepresence on consumer responses. The author found that user control and media richness are significant antecedents of telepresence and they had significant positive influences on the creation of telepresence.

Fiore and Jin (2003) examined the effect of one aspect of interactivity, "image interactivity" of apparel websites on consumer responses. The authors defined image interactivity technology (IIT) as "the ability to create and manipulate images of a product or environment on a web site”. P: 38). The authors found a positive relationship between IIT and patronizing clothes online retailer's bricks-and-mortar stores.

Song, Fiore and Park (2007) have investigated the impact of consumers' product simulation experience (telepresence) and fantasy on consumer responses. The results showed that telepresence affects fantasy and consumers' hedonic value.

In 2004, Lee (2004) revised all the previous definitions of telepresence or presence and he argued that none of the previous definitions could be used to tap the concept of using virtual environment to reflect the consumer experience. The author stated two ways for an experience to become a virtual one; firstly, using "Para-authentic objects" in which the users interact with objects in which they can find in real life aspects such as clothes. Secondly, using "Artificial objects", which simulates objects that do not exists in real life.

\subsection{Authenticity Construct}

None of the previous definitions of telepresence that use 3D virtual models can tap consumers' virtual experiences though. Based on Lee's (2004) theoretical study, regarding authentic objects, and Klein's (2003) study, regarding realism construct. A 3D virtual experience should be an authentic representation of the direct (offline) experience. We therefore propose a new notion that relates to the simulation of online products and virtual experience, namely, the authenticity of the product visualisation. Telepresence and presence 
are not particularly well suited to the online retail context, because they reflect illusion and transportation to other places. In contrast, the concept of $3 \mathrm{D}$ authenticity of the product visualisation implies that ability to simulate the product experience in bricks-and-clicks contexts. We propose the following definition of perceived authenticity in a computermediated environment: Authenticity is a psychological state in which virtual objects presented in $3 D$ in a computer-mediated environment are perceived as actual objects in a sensory way. To determine the influences of telepresence and authenticity on consumers' experiences in an online retail context, we investigate the following research questions:

First, how do consumers perceive $3 D$ product virtualisation (telepresence) compared with $3 D$ product authenticity on online retailers' Web sites?

Second, does authenticity of $3 D$ product virtualisation on a retailer Web site affect consumers' virtual experiences (affective and cognitive parts)?

On the basis of our definitions of telepresence and authenticity, we posit that

$H_{A}$ : On the online retailer's Web site, 3D authenticity has a greater effect on users than does $3 D$ telepresence.

\subsection{Conceptual framework:}

Figure 1: conceptual framework (source: the authors).

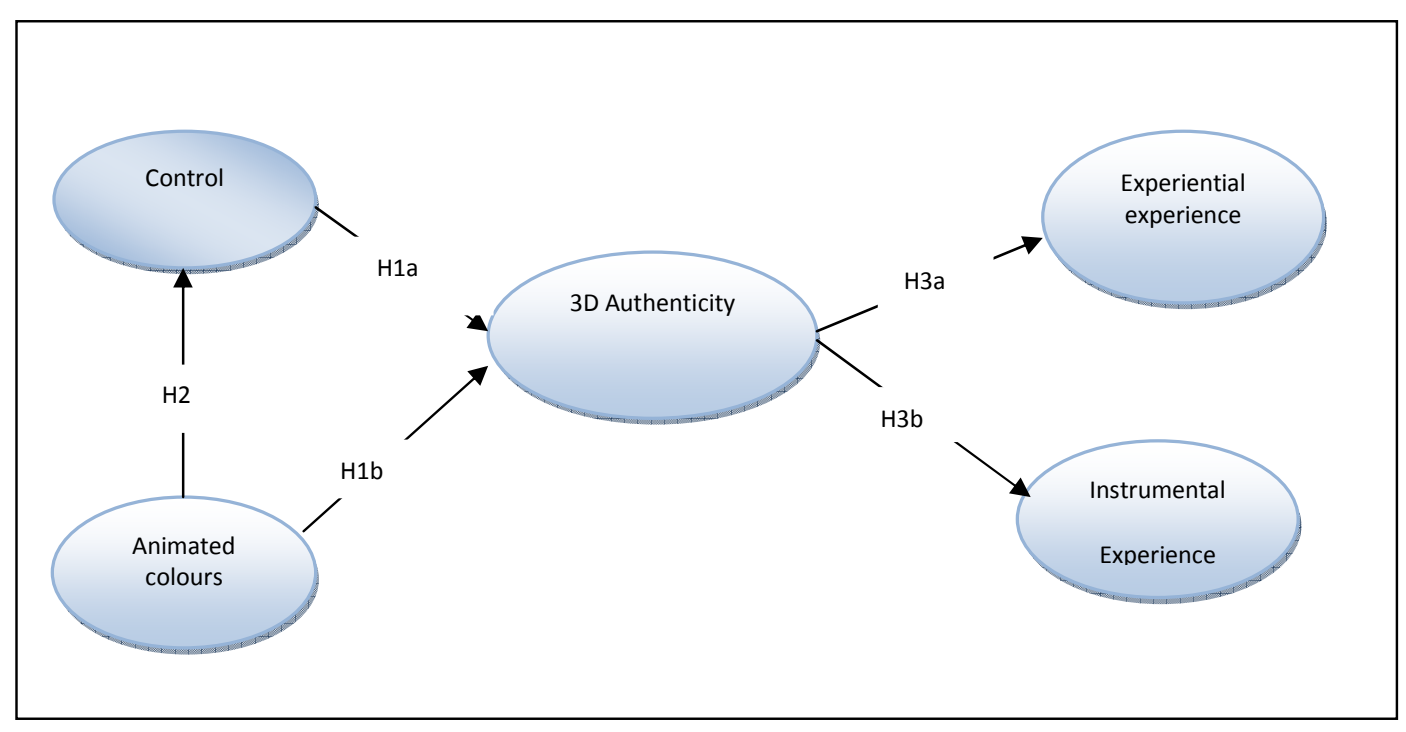

\subsection{Authenticity Antecedents}


Given that 3D virtual model, on a retailer Web site, interactivity (i.e., users' ability to modify the form and content of a mediated environment in a real time) and vividness (i.e., breadth and width of the stimulus) influence consumers' sense of authenticity or realism (Klein, 2003; Lee, 2004). We focused on the control construct as representative of interactivity within the online retail context. Airely's (2000) definition of control refers to users' ability to customize and choose the contents of a website to achieve consumers' goals. We, in the context of virtual models, focused more on defining the control construct to suit consumers' ability to control and easily interact with the 3D virtual model. We define control as users' ability to customize and choose the contents of the virtual model (i.e., 3D product visualisation), users' ability to change colours, rotate, zoom in/ out the product in the virtual model and the ability of the virtual model (3D) to respond to participants' orders properly. Based on the above we hypothesize:

HIa: A high level of control of $3 D$ product visualisation increases authenticity.

Furthermore, since 3D in the online retailer need visual and auditory channels for facilitating consumers' vividness; others manifestly need only visual aspects. We focus on one aspect of vividness, namely, breadth, while holding depth constant. Moreover, we focus on one aspect of vividness breadth, namely, animated colours. Animated coloured pictorial images used in this study to represent consumers' ability to see 3D products with different animated skins. High-quality online animated colours may enhance consumers' authenticity perception (e.g., Fortin and Dholakia, 2003; Klein, 2003; Shih, 1998) and we hypothesise:

\section{H1b: A high level of 3D animated colours increases perceived authenticity.}

Specifically, we consider vividness of the visual imagery, such that consumers can see online products with different colours (skins) just as they would see them in person. Media richness may lead to telepresence, according to research on online shopping (Klein, 2003; Schlosser, 2003). Moreover, consumers' ability to change the animated colours of the 3D product might help them sense control over the product. We therefore hypothesise:

H2: the animated colours increase controlling 3D product visualisation.

\subsection{Authenticity Consequences}


Scholars (e.g., Fiore and Jin, 2003; Fiore et al., 2005a; Kim et al., 2007; Klein, 2003; Li et al., 2001; 2002, 2003; Suh and Chang 2006) explain the importance of using 3D product visualisations in enhancing consumers' understanding of product attributes, features and characteristics. 3D visualisation increases consumers' involvement and encourages them to seek more information about the products (Fiore et al., 2005a). Suh and Lee (2005) posit a positive relationship between higher levels of $3 \mathrm{D}$ product visualisation and seeking more information about the products' characteristics and features. Suh and Chang's (2006) empirical research of the influence of $3 \mathrm{D}$ product visualisation and product knowledge reveals a positive relationship between 3D and perceived product knowledge. Using 3D product visualisation helps consumers to imagine how a product may look and it gives them more details about the products' characteristics (Fortin and Dholakia, 2003; Klein, 2003; Shine, 1998). Many scholars in the communication field (e.g., Heeter, 1992; Lombard and Ditton, 1997; Song et al., 2007) have reported the importance of enjoyment as a consequence of using 3D. Based on the above, we hypothesize:

H3a: 3D authenticity in a retailer website will positively affect website use for experiential value.

Scholars (Fiore et al., 2005b; Kim and Forsythe, 2007; Lee et al., 2006; Schlosser, 2003) report the importance of 3D product visualisation in enhancing the experiential aspects of a virtual shopping. The above researchers find the ability of 3D product visualisation to produce hedonic values for shoppers greater than its ability to produce utilitarian values. Fiore et al. (2005b) assert hedonic value, which image interactivity technology produces, is highly correlated with consumers' emotional pleasure and arousal variables. Fiore et al. (2005a) posit the importance of virtual models in boosting hedonic value (enjoyment). Fiore et al. (2005a) report the importance of a high level of image interactivity technology in comparison to a low level of image interactivity technology (in the high level conditions, consumers could only enlarge the static picture of cloths) in producing more hedonic value. Many scholars in the communication field (e.g., Heeter, 1992; Lombard and Ditton, 1997; Song et al., 2007) delineate the importance of enjoyment as a consequence of using 3D. Consumers use 3D product visualisation to have more fun, enjoyment and entertainment (Kim and Forsythe, 2007). Such sources of fun or enjoyment come from consumers' ability to rotate, and zoom in or out on the product (Fiore et al., 2003), seeing different animated 
coloured pictorial images that may enhance their mental pleasure when using 3D sites. Therefore, we hypothesise:

H3b: 3D authenticity in a retailer website will positively affect website use for instrumental value.

\subsection{Methods}

\subsection{Stimuli}

A retailer's website with one stimulus was custom-designed for this study. The stimulus was illustrated in 3D product visualisation sites in which participants can see, the focal product, laptops from different angles; they can rotate it and zoom it in or out. The 3D stimulus is designed to help consumers to imagine the product in appropriate and relevant ways and it enhances consumers' virtual experiences ( $\mathrm{Li}$ et al., 2001).

\subsection{Experimental Procedure}

To eliminate individual differences, we employed a within-subjects design for all the experimental conditions. Each subject therefore represents his or her own control (Greene and d'Oliveira, 1999). This design increases the statistical power of the experiment, because we require fewer subjects than we would for a between-subjects design. Moreover, it helps reduce error variance (associated with individual differences). Finally, the design helps reduce costs because we take several observations from the same subject (Greenwald, 1976; Keppel and Wickens, 2004). Most previous research in this field has used either a betweensubjects or mixed design (e.g., Fiore and Jin, 2003; Fiore et al., 2005a; Li et al., 2002; Kim et al, 2007; Suh and Chang, 2006).

\subsection{Interface Design}

Four 3D flashes (sites) were designed for the 3D product visualisations. The first flash contained a laptop that participants can zoom in/out, rotate, change the colour of the laptop case and get information about the laptop (i.e., features and attributes). The second flash has a laptop that participants can zoom in/out rotate and they can change the colour of the laptop case but with only limited information about the external appearance of the laptop (i.e., participants can only close and open the laptop). The third flash has a laptop that participants 
can only zoom in/out and rotate, but they cannot change the laptop colour. The final condition is a laptop that participants can do nothing with, that keeps rotating in front of the participants. The above 3D sites, particularly the flash that contained information distinguished the current research from the previous research that reported the significant role of $3 \mathrm{D}$ in enhancing fun and enjoyment values more than utilitarian values (e.g., Schlosser, 2003; Fiore et al., 2005b; Lee, et al., 2005; Kim and Forsythe, 2007) .

In designing the interfaces, this research makes sure to include almost all the types of visualisation that a consumer may find in any electrical online retailer. Moreover, this study adds more features and cases to the ones that might be found in real sites. For example, none of the national sites that sell laptops (e.g., Sony and Dell) has a flash combining both 3D and information about laptops. Electrical retailers and specially laptops have been chosen as our hypothetical retailers. Laptops industry has been chosen in this study due to its importance. in other words, based on Image Marketing Retailer Group (IMRG, 2008) Capgemini e-Retail Sales Index, which shows that number of U.K. online shoppers increases steadily, online spending by U.K. consumers has broken previous records, racking up $£ 4.2$ bn in sales in February 2008, this equates to $£ 69$ for every person in the U.K. and represents an increase of 46 per cent compared to February 2007. Moreover, IMRG stated that both electricals and clothing are the favourite purchases among U.K. shoppers, with 38 per cent and 32 per cent share of revenues respectively.

\subsection{Experimental Design}

The Web site we created for this study was not previously known to users, nor did users have any knowledge of the fictitious brands on the site. Thus, we eliminated any impact of previous experiences or attitudes (Fiore et al., 2005a). The site offers a wide variety of laptops, similar to those that many college-aged women and men currently buy and use. Therefore, site provides a suitable context for the present sample.

We designed three separate experiments. The first experiment serves two objectives: It tests $\mathrm{H}_{1 \mathrm{a}}$ and $\mathrm{H}_{1 \mathrm{~b}}$ and it illustrates the importance of different levels of control and animated colours, as well as and their impact on perceived authenticity. We manipulated two constructs: control (high versus low) and animated colours (high versus low). 
In the second experiment, we test $\mathrm{H}_{\mathrm{A}}$ by asking 312 students to determine the significance of authenticity and telepresence in simulating the laptops. Finally, in the third experiment, the same 312 participants, who attend a London (U.K.) university, indicate the impact high control and animated colours on 3D authenticity, and the impact of 3D authenticity on experiential and instrumental values.

\subsection{Sample}

Student samples have often been used in online shopping research (e.g., Li et al., 2002; 2003; Fiore et al., 2005; Kim et al., 2006; Balabanis and Reynolds, 2001) this is justifiable as students are computer-literate, having few problems in using new technology. Students are potential consumers of electrical goods (Jahng, Jain and Ramamurthy, 2007). We employed a sample of 24 post graduate students to do the manipulation checks and 312 students for the other experiments. Finally, data collection started in January and ended in February 2009.

\subsection{Time}

Time exposure to a stimulus influences users' end responses (Zajonc, 2001), so several studies attempt to determine the appropriate time exposure to an online stimulus (e.g., Fiore and Jin, 2003; Fiore et al., 2005a; Kim et al., 2007). We followed these studies and set a time limit on the exposure in each experiment of five minutes. After viewing the stimuli for this time, the subjects completed a questionnaire.

\subsection{Instrument}

Participants were informed that the study concerned consumers' evaluation of an electrical retailer's website. The questionnaire used 5- point Likert-type scales anchored by "strongly disagree" to "strongly agree".

To measure the control construct, a scale was developed to match consumers' ability to control the 3D flashes. To measure the animated colours construct, a modified version of Klien's (2003) and Sturate's (1992) scales was used. To measure experiential and instrumental values Babin's et al. (1994) scale and Fiore's et al. (2005) scale based on modifications of Babin's et al. scale was used. To measure telepresence a modified version of Kim and Biocca's (1997) scale was used. To measure authenticity, we could not find an existing scale to measure authenticity so we developed a new five-item scale. We submitted the items to evaluations by academics (lecturers in online retailing and $\mathrm{Ph} . \mathrm{D}$. students); these 
respondents considered the items relevant for measuring the authenticity construct. We followed Churchill's (1979) procedures for developing a marketing construct scale and adopted George and colleagues (2004) procedures for developing a scale for the online context (see Table 1).

\section{Results}

\subsection{Experiment 1}

Figure 2 the mean and Standard deviations for the four conditions

\begin{tabular}{|l|l|r|r|}
\hline \multicolumn{3}{|c|}{ 1. Descriptive Statistics } \\
\hline Condition & Mean & $\begin{array}{c}\text { Std. } \\
\text { Deviation }\end{array}$ & $\mathrm{N}$ \\
\hline High control, high animated colour & 19.5833 & 3.54985 & 24 \\
High control, Low animated colour & 14.4167 & 4.49073 & 24 \\
Low control, High animated colour & 13.2500 & 3.54168 & 24 \\
Low control, Low animated colour & 10.0833 & 3.74069 & 24 \\
\hline
\end{tabular}

We ran a two-way repeated measures ANOVA to compare the scores for the two levels of control and two levels of animated colours (2control $\times 2$ animated colours), with 3D authenticity as the dependent variable. The main effect of the control levels is significant. We find a Wilks' Lambda value of: .275, F $(1,23)=60.778(p<.001)$, and an eta squared value of .725 (which is a large effect size according to Cohen, 1988). The means (M) and standarderrors (SE) of the control levels are as follows: $\mathrm{M}_{\text {high }}=17, \mathrm{SE}_{\text {high }}=.551, \mathrm{M}_{\text {low }}=11.7$ and $\mathrm{SE}_{\text {low }}=.68$. The main effect of animation also is significant, with a Wilks' Lambda of: .40, $\mathrm{F}$ $(1,23)=34.6(\mathrm{p}<.001)$, and an eta squared value of .60. The means and standard errors are $\mathrm{M}_{\text {high }}=16.42, \mathrm{SE}_{\text {high }}=.54, \mathrm{M}_{\text {low }}=12.3$, and $\left.\mathrm{SE}_{\text {low }}=.704\right)$. The results also indicate an insignificant interaction effect (control $\times$ animation; $\mathrm{F}(1,23)=2.272, p>.05, e^{2} a^{2}=.090$ ). Participants exposed to the condition with high control and high animated colours agreed that the site attained high authenticity $(\mathrm{M}=16.6, \mathrm{SD}=3.55)$, but the site with low levels of control and animated colours achieved a low level of authenticity $(\mathrm{M}=10.1, \mathrm{SD}=3.47)$. The high level of control and low level of animated colours $(\mathrm{M}=14.4167, \mathrm{SD}=4.49)$, and low level of control and high level of animated colours $(\mathrm{M}=13.25, \mathrm{SD}=3.54)$ also prompted ratings of a low level of authenticity. Overall, these results indicate that authenticity increases when control and animated colour levels increase. The participants noticed the manipulated conditions, and the results support $\mathrm{H}_{1 \mathrm{a}}$ and $\mathrm{H}_{1 \mathrm{~b}}$. 


\subsection{Experiment 2}

We ran a one-way repeated measure ANOVA to compare the scores for the telepresence and authenticity constructs. Participants agreed that the site is best represented by authenticity (M $=18.44)$ rather than by telepresence, that is, by a sense of being transported into another place $(\mathrm{M}=12.01)$. The Wilks' Lambda is $.2764, \mathrm{~F}(1,311)=814.078,(p<.001)$, and the multivariate eta squared is .724, which reflects a very large effect size (Cohen, 1988). The results of the post hoc analysis also reveal that authenticity is more significant than telepresence $(p<.001)$, in support of $\mathrm{H}_{\mathrm{A}}$.

\subsection{Experiment 3}

\subsubsection{Measurement Model}

AMOS 16 was used to test the overall goodness of fit of the conceptual model using 312 participants. The measurement model includes 19 indicators, and we provide its results in Table 1, including the standardised factor loading, standard error, t-values, average variance extracted and composite reliability for each construct. The standardised factor loadings $(\lambda)$ are all greater than .60. The composite reliabilities for animated colours (.70), control (.81), authenticity (.88), instrumental value (.86) and experiential value (.86) all are acceptable (Hair et al., 2006). Figure 3 illustrates path coefficients and $\mathrm{R}^{2}$ for the effects of control, animated colours and authenticity on values, all the paths are valid.

Figure 3: showing structural path coefficients and $\mathrm{R}^{2}$ for the effects of control, animated colours and authenticity on values.

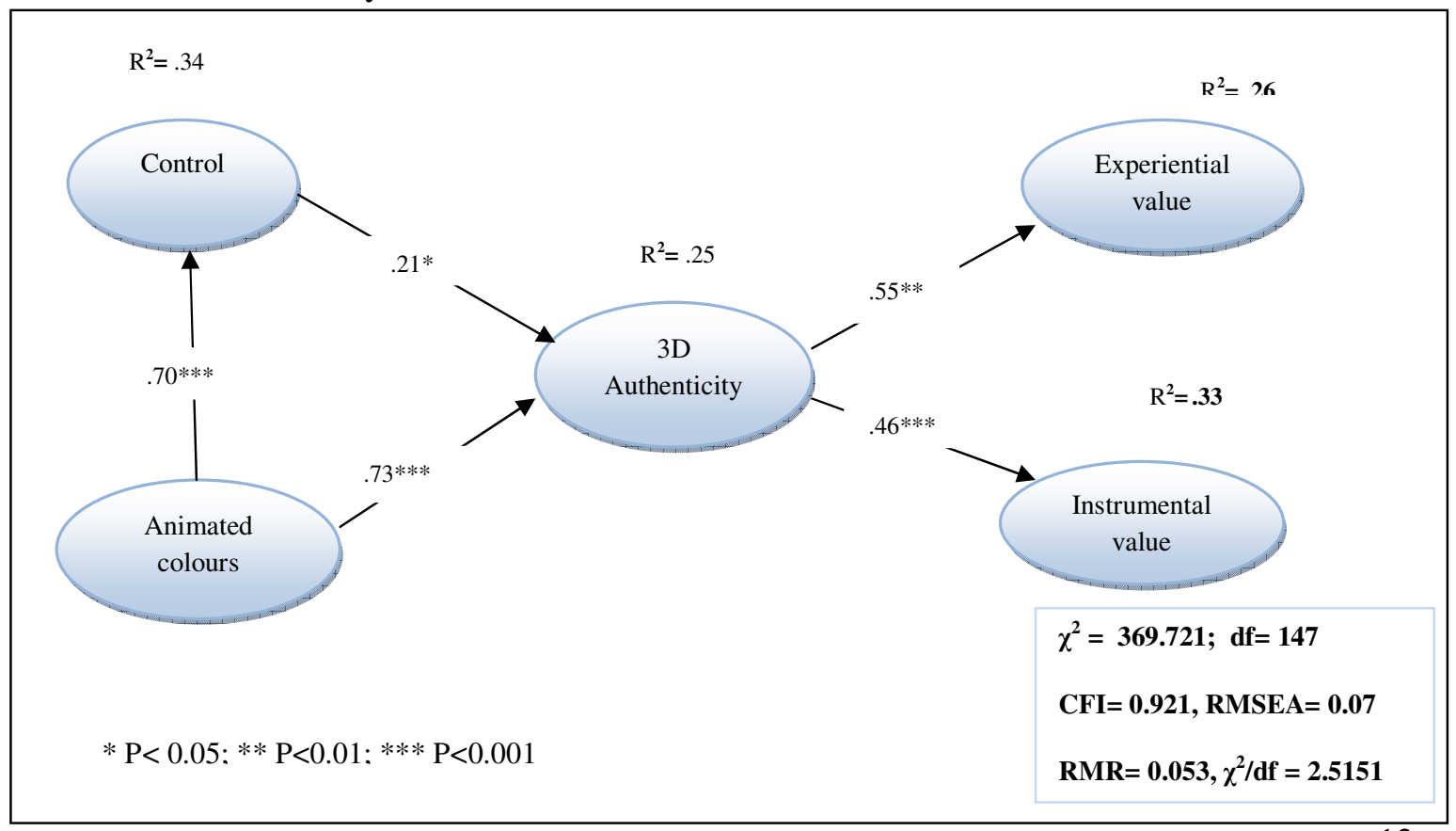


Table 1: measurement model results for hypothetical model with new factor structures.

\begin{tabular}{|c|c|c|c|c|c|c|}
\hline Construct indicator & $\begin{array}{l}\text { Standardized } \\
\text { factor loading }(\lambda)\end{array}$ & S.E & C.R & $\begin{array}{l}\text { Average } \\
\text { Variance } \\
\text { extracted }\end{array}$ & $\begin{array}{l}\text { Squared } \\
\text { multiple } \\
\text { correlation }\end{array}$ & $\begin{array}{l}\text { Composite } \\
\text { reliability }\end{array}$ \\
\hline $\begin{array}{l}\eta 1 \text { (control) } \\
\text { - I felt that I could choose freely what I } \\
\text { wanted to see }\end{array}$ & .777 & - & & 0.5224 & 0.37 & 0.813 \\
\hline $\begin{array}{l}\text { - I felt that I had a lot of control over the } \\
\text { content of the laptop's options (i.e. angles } \\
\text { and information) }\end{array}$ & .781 & 0.077 & 12.018 & & 0.51 & \\
\hline $\begin{array}{l}\text { - I felt it was easy to rotate the laptop the } \\
\text { way I wanted. }\end{array}$ & .710 & 0.077 & 9.924 & & 0.51 & \\
\hline $\begin{array}{l}\text { - I felt I could control the laptop } \\
\text { movements. }\end{array}$ & .610 & 0.072 & 8.882 & & 0.60 & \\
\hline $\begin{array}{l}\eta 2 \text { (animated colours) } \\
\text {-There are lots of colours on 3D laptop } \\
\text { websites. }\end{array}$ & .714 & - & & 0.40 & 0.21 & 0.7 \\
\hline $\begin{array}{l}\text { - Colours brightness of the } 3 \mathrm{D} \text { laptop let } \\
\text { me visualize how the real laptop might } \\
\text { look. }\end{array}$ & .655 & 0.104 & 8.552 & & 0.43 & \\
\hline $\begin{array}{l}\text { - The laptop illustrated by 3D was very } \\
\text { colourful }\end{array}$ & .459 & 0.081 & 6.335 & & 0.51 & \\
\hline $\begin{array}{l}\eta 3 \text { (Authenticity) } \\
\text { - 3D Creates a product experience similar } \\
\text { to the one I would have when shopping in a } \\
\text { store. }\end{array}$ & .764 & - & & 0.643 & 0.66 & 0.8777 \\
\hline $\begin{array}{l}\text { - 3D Let me feel like if I am holding a real } \\
\text { laptop and rotating it (i.e. virtual } \\
\text { affordance) }\end{array}$ & .761 & 0.078 & 13.706 & & 0.74 & \\
\hline $\begin{array}{l}\text { - 3D Let me feel like I am dealing with a } \\
\text { salesman who is responding to my orders. }\end{array}$ & .862 & 0.080 & 15.360 & & 0.58 & \\
\hline $\begin{array}{l}\text { - 3D let me see the laptop as if it was a real } \\
\text { one. }\end{array}$ & .815 & 0.078 & 14.580 & & 0.58 & \\
\hline $\begin{array}{l}\eta 3 \text { (Experiential value) } \\
\text { - Would be like an escape. }\end{array}$ & .706 & - & & 0.615 & 0.68 & 0.8571 \\
\hline - Would be truly enjoyable & .741 & 0.076 & 12.125 & & 0.68 & \\
\hline $\begin{array}{l}\text { - Would be enjoyable for its own sake, not } \\
\text { just for the items I may have purchase. }\end{array}$ & .823 & 0.090 & 12.746 & & 0.55 & \\
\hline $\begin{array}{l}\text { - Would let me enjoy being immersed in an } \\
\text { existing new product. }\end{array}$ & .822 & 0.090 & 12.682 & & 0.50 & \\
\hline $\begin{array}{l}\eta 4 \text { (instrumental value) } \\
\text { - Help me make a better decision about the } \\
\text { product. }\end{array}$ & .786 & - & & 0.611 & 0.62 & 0.8616 \\
\hline - help me buy the right product. & .766 & 0.062 & 13.750 & & 0.60 & \\
\hline - Aid me in evaluating the laptop items. & .776 & 0.066 & 12.859 & & 0.59 & \\
\hline - Help me in finding what I am looking for & .786 & 0.072 & 13.229 & & 0.62 & \\
\hline
\end{tabular}




\subsubsection{Structural Equation Model}

The adequacy of the hypotheses was assessed by using CFI, RMSEA and RMR to test the overall goodness of fit of the proposed conceptual model. The results of structural equation modelling obtained for the proposed conceptual model revealed a chi-square of 369.721 ( $\mathrm{df}=$ 147), goodness of fit index (GFI) of .889, comparative fit index (CFI) of .921, root mean square residual (RMR) of .053. Indicating a good model fit (Byrne, 2001; Hair et al., 1998). All hypotheses of the conceptual model were statistically supported $(p<.05)$. Figure 3 shows that control and animated colours had significant positive effects on authenticity (H1a: $\mathrm{CR}=$ 2.426; H1b: $\mathrm{CR}=6.069$ ). Moreover, animated colours exhibited a significant positive effect on control $(\mathrm{H} 2: \mathrm{CR}=6.738)$. Finally, as hypothesized, 3D authenticity has a significant positive effect on experiential and instrumental values $(\mathrm{H} 3 \mathrm{a}: \mathrm{CR}=8.852$; $\mathrm{H} 3 \mathrm{~b}$ : $\mathrm{CR}=7.537)$.

\section{Discussion and Conclusion}

Although the generalisability of the results is limited by the student sample, we argue that students are computer literate and have few problems using new technology; students also are likely consumers of electrical goods and they represent the shoppers of today and tomorrow (Balabanis and Reynolds, 2001). Furthermore, this research highlights the importance of the authenticity construct for 3D product visualisation. Our authenticity scale is suitable and convenient for academics and practitioners interested in using 3D to simulate real products in the online retail context. Moreover, we find that control provides a useful representation of the interactivity of 3D virtual models. Finally, we clarify the main differences between authenticity and telepresence; telepresence involves illusion or a sense of being transported to another place, whereas authenticity refers to the ability to imagine a virtual object as real.

The antecedents of authenticity (i.e., control and animated colours) seem similar to those of telepresence (e.g., Fiore et al., 2005a; Klein, 2003). However, when investigating the antecedents of authenticity, researchers should focus on certain real elements of interactivity and vividness rather than on the abstract constructs. Whereas Heeter (2000, p. 75) describes interactivity as "an overused and underdefined concept", we posit that control represents a useful construct for 3D models in the online retail context, in support of previous research (Ariely, 2000; Coyle and Thorson, 2001). We narrow our conceptualisation of control to consumers' ability to control 3D flashes. Furthermore, whereas prior research defines 
vividness according to sensory breadth and depth, we argue that research might benefit from a tighter focus on specific aspects of vividness through illustration, as we have. Animated colours also have a significant effect on authenticity.

Results of this research (authenticity consequences) support the past research that reports the ability of 3D to provide customers with more information and fun (e.g., Fiore et al., 2005a; 2005b). Moreover, the way that we designed the 3D flashes and the authenticity of the flashes in simulating a real laptop gives this research more validity in providing consumers with more information. In contrast, as a result of focusing on the telepresence construct, previous research has focused on the importance of the experiential value that consumers can gain from navigating 3D products more than the instrumental value (e.g., Schlosser, 2003; Fiore et al., 2005b; Lee, et al., 2005; Kim and Forsythe, 2007). The authenticity construct reveals the importance of information as well as fun for users.

Our results answered Eroglu and colleagues (2003) recommendations to focus on specific aspects of the online retailer atmosphere. The results show the importance of focusing on one stimulus, namely, 3D and the significance of this stimulus to enhance consumers' perceptions and virtual experiences once navigating the 3D online retailer. Moreover, the results show that consumers' experience with the 3D product visualisation could be an objective of the participants via their exposing to our cues (3D flashes) or it could be an outcome to the shopping activity (Demangeot and Broderick, 2006).

On the bases of our results, we recommend that Web site developers should pay more attention to simulating 3D animated colours to reflect the real products more authentically. Moreover, they should work to create an environment in which consumers sense that they can feel the online products when they navigate the site. Further research should consider whether adding auditory cues to the 3D flashes influence behavioural intentions. Finally, we recommend research efforts to extend the generalisability of our findings to other contexts and samples since we designed and collected the data using a mock up retail website (which might consider as one of this research limitation). 


\section{References}

Ariely, D. (2000) Controlling the information flow: Effects on consumers' decision making and preferences, Journal of Consumer Research, 26(sep.), pp. 233-248

Babin, B., Darden, W., and Griffin, M. (1994) Work and/or fun: measuring hedonic and utilitarian shopping values, Journal of Consumer Research, 20(4), pp. 644-565.

Biocca, F. (1997) The cyborg's dilemma: progressive embodiment in virtual environments, Journal of Computer-Mediated Communication. 3(2) Available:http://www.ascusc.org/jcmc/vol3/issue2/biocca2.html

Biocca, F. (1992) Will simulation sickness slow down the diffusion of virtual environment technology? Presence, 1(3), pp. 334-343.

Cohen, J. (1988) Statistical power analysis for the behavioral sciences, $2^{\text {nd }}$ Ed, Hillsdale, NJ: Lawrence Earlbaum Associates.

Demangeot, C., and Broderick, A. (2006), "Exploring the experiential intensity of online shopping environments", Journal of qualitative marketing research, Vol. 9, No. 4, pp. 325-351.

Downes, E., and McMillian, S. (2000) Defining interactivity a qualitative identification of key dimensions, Journal of New Media and Society, 2(2), pp. 157-179.

Eroglu, S.A., Machleit, K.A. and Davis, L.M. (2003), "Empirical testing of a model of online store atmospherics and shopper responses", Psychology and Marketing, Vol.29, No. 2, pp. $139-150$

Fiore, A. M., Kim, J. and Lee, H.H .(2005a) Effects of image interactivity technology on consumer responses toward the online retailing, Journal of Interactivity Marketing, 19(3), pp. 39-53.

Fiore, A., Jin, H. and Kim, J. (2005b) For fun and profit: hedonic value from image interactivity and responses towards an online store, Psychology \& Marketing, 22(8), pp. 669-94.

Fiore, A.M., \& Jin, H.J. (2003) Influence of Image Interactivity on Approach Responses Towards an Online Retailer'. Internet Research: Electronic Networking Applications and Policy, 13, pp. 38-48

Fortin, D., and Dholakia, R. (2005) Interactivity and vividness effects on social presence and involvement with a web-based advertisement, Journal of Business Research, 58, pp. 387396. 
Greene, J., and d'Oliveira, M. (1999) Learning to use statistical tests in psychology, $2^{\text {nd }}$ edition, Open University press, Maidenhead, Philadelphia.

Greenwald, A. (1976) Within-subjects design: To use or not to use?, Psychology Bulletin, 83(2), pp. 314-320.

Hair, J., Anderson, R., Tatham, R., and Black, W. (1998) Multivariate Data Analysis, Prentice-Hall, Upper Saddle River, NJ.

Heeter, C. (1992) Being there: the subjective experience of presence'. Presence:

Teleoperators and Virtual Environments, 1, pp. 262-71.

Hopkins, C. D., Raymond, M, A., Mitra, A. (2004) Consumer Responses to perceived telepresence in the online advertising environment: the moderating role of involvement, Marketing Theory, 4(137), pp. 137-63.

Jahng, J., Jain, H., \& Ramamurthy, K. (2000) Effective design of electronic commerce environments: A proposed theory of congruence and an illustration'. IEEE Transactions on Systems, Man, and Cybernetics: Part A'. 30(July), pp. 456-471.

Keppel, G., and Wickens, T. (2004) 'Design and analysis a researcher's handbook', Person Prentice Hall, New Jersey, USA.

Kim, J \& Forsythe, S. (2007) Hedonic usage of product virtualisation technology in online apparel shopping'. International Journal of Retail and Distribution Management, 35(6), pp. 502-514.

Kim, J., Fiore, A., and Lee, H. (2007) Influence of online store perception, shopping enjoyment, and shopping involvement on consumer patronage behaviour towards an online retailer'. Journal of Retailing and Consumer Services, 14, pp. 95-107.

Kim, T., and Biocca, F. (1997) Telepresence via Television: tow dimensions of telepresence may have different connections to memory and persuasion, Journal of Computer-Mediated Communication, 3(2), http://www3.interscience.wiley.com/cgibin/fulltext/120837731/HTMLSTART

Klein, L. (2003) Creating virtual product experiences: the role of telepresence'. Journal of Interactive Marketing, 17(1), pp. 41-55.

Lee, H., Fiore, A., and Kim, J. (2006) The role of the technology acceptance model in explaining effects of image interactivity technology on consumer responses, International Journal of Retail \& Distribution Management, 34(8), pp. 621-644.

Lee, K. (2004), Presence, Explicated, Communication Theory, 14(1), pp. 27-50. 
Li, H., Daugherty, T. and Biocca, F. (2001) Characteristics of virtual experience in electronic commerce: a protocol analysis, Journal of Interactive Marketing, 15(3), pp. 13-30.

Li, H., Daugherty, T. and Biocca, F. (2002) Impact of 3-D advertising on product knowledge, brand attitude and purchase intention: the mediating role of presence, Journal of Advertising. 31(3): 43-57.

Li, H., Daugherty, T. and Biocca, F. (2003), The role of virtual experience in consumer learning'. Journal of Consumer Psychology. 13(4), pp. 395-407.

Liu, Y. and Shrum, L.J. (2002) What is interactivity and is it always such a good thing? Implications of definition, person, and situation for the influence of interactivity on advertising effectiveness, Journal of Advertising. 31(4), pp. 53-64.

Lombard, M and Ditton, T. (1997), At the heart of it all: the concept of presence, Journal of Computer-Mediated Communication. 3(2):

http://jcmc.indiana.edu/vol3/issue2/lombard.html

McMillan, S.J. (2002) A four-part model of cyber-interactivity, Journal of New Media and Society, 4(2), pp. 271-291

McMillan, S.J. and Hwang, J.-S. (2002) Measures of perceived interactivity: an exploration of the role of direction of communication, user control, and time in shaping perceptions of interactivity, Journal of Advertising, 31 (3), pp. 29-42.

Rafaeli, S. (1988) Interactivity: from new media to communication”, in Hawkins, R.P., Wiemann, J. and Pingree, S. (Eds), Advancing communication science: Merging Mass and interpersonal processes, Sage publications, Newbury Park, CA, pp, 110-134.

Rafaeli, S. and Sudweeks, F. (1997) Networked interactivity. Journal of Computer Mediated Communication, 2 (4): http://jcmc.indiana.edu/vol2/issue4/rafaeli.sudweeks.html

Schlosser, A. (2003) Experiencing products in the virtual world: the role of goal and imagery in influencing attitudes versus purchase intentions, Journal of Consumer Research, 30(2), pp. 184-198.

Sheridan, T.B. (1992) Musings on telepresence and virtual presence, Presence Teleoperators and Virtual Environments, 1(1), pp. 120-126.

Shih, C. (1998) Conceptualizing consumer experiences in cyberspace, European Journal of Marketing, 32(7/8), pp. 655-663

Song, J., and Zinkhan, G. (2008) Determinants of perceived web site interactivity, Journal of Marketing, 72(March), pp. 99-113

Song, K., Fiore, A., and Park, J. (2007) Telepresence in online apparel shopping experience, Journal of Fashion Marketing and Management, 11(4), pp. 553-570. 
Steuer, J. (1992) Defining virtual reality: dimensions determining telepresence, Journal of Communication. 42(4), pp. 73-93.

Suh, K., and Chang, S. (2006) User interface and consumer perceptions of online stores: the role of telepresence, Journal of Behaviour \& Information Technology, 25(2), pp. 99-113.

Suh, K., and Lee, Y. (2005) The effects of virtual reality on consumer learning: an empirical investigation, MIS Quarterly, 29(4), pp. 673-697.

Witmer, B., and Singer, M. (1998) Measuring presence in virtual environments: a presence questionnaire', Presence, 7(3), pp. 225-240

Zajonc, R. B. (2001) Mere exposure: a gateway to the subliminal, Current Directions in Psychological Science. 10(6), pp. 224-228. 